\title{
Perfumadores, fruteros y confiteros: recipientes para exhibir el lujo sensorial entre la nobleza castellana del siglo $\mathrm{XV}$
}

\author{
Laura Ma Vegas Sobrino \\ Universidad de Valladolid \\ Departamento de Historia del Arte, JCyL y Fondo Social Europeo \\ lauravegassobrino@hotmail.com \\ María Teresa ViÑAs TORRES \\ Máster en Métodos y Técnicas Avanzados de Investigación, UNED \\ Posgrado Experto en Gestión Documental de Museos, Universidad de Alcalá de Henares \\ teresatorres1985@hotmail.com
}

\begin{abstract}
RESUMEN
Perfumes y confites fueron dos de los elementos esenciales para la magnificencia en los ambientes de la alta nobleza castellana del s. XV, en torno a los cuales se creó toda una serie de objetos en materiales preciosos y exclusivos, además de ricamente decorados, que constituyen una fuente imprescindible para acercarse a la sensorialidad del lujo en su dimensión olfativa y gustativa.

Pese a que todo indica que unos y otros eran ineludibles para el vestido de las principales casas y guardarropas aristocráticos, en la actualidad apenas se conocen más que por referencias cronísticas muy parciales, en las que por otra parte su suntuosidad parece darse por sentada sin profundizar en los detalles. Sin embargo, su rastro puede seguirse en el mobiliario textil creado para su exhibición, o en las piezas de joyería y orfebrería diseñadas para contenerlos, que aparecen en testamentos, inventarios, codicilos y registros de cámara. En estos documentos se mezclan con útiles y afeites en arcas ricas, joyas, vajilla, manteles y paños de mesa, con los que en ocasiones parecen formar un conjunto. Se mencionan sus formas, materiales, precios de compra, y a veces incluso partes de sus procesos de producción, o los profesionales encargados de su diseño y realización.

Interpretando y contextualizando estos datos, se describen algunas de las características formales de joyas con ámbar, bujetas, aguamanos, fruteros y confiteros de dulces, y otros objetos de mesa o cámara con los que se pueden relacionar estética o funcionalmente, de los que los vestigios conservados son casi nulos.

Su importancia, más allá de su elaborada estética y valor económico, reside en la exclusividad de su uso. Muchas fueron piezas indispensables del ajuar que componía una mesa noble, resultando elementos clave dentro de este ámbito; su utilización distinguía al señor o señora que se servía de ellos, de acuerdo a unas pautas establecidas.
\end{abstract}

Palabras clave: Perfumeros, confiteros, sensorialidad, Corte de Castilla, s. XV. 


\title{
Perfume Bottles, Fruit Bowls, and Comfit Boxes: Containers for the Expression of Sensory Luxury Among the $15^{\text {th }}$ Century Castilian Nobility
}

\begin{abstract}
Perfume and comfits were two essential elements of magnificence present in the midst of a highly noble Castilian society during the $15^{\text {th }}$ century, around which were created a number of items in beautiful and unique materials which, along with being richly decorated, served as containers and constituted an essential source to enable us to come close to their sensory dimension of luxury in smell and taste.

Although it appears that both elements would have been inevitable in the decoration of major aristocratic homes and dressing rooms, little more is known apart from through biased contemporaneous references that seem to take for granted the sumptuousness with little regard for specific physical detail. However, a clearer picture can be formed by the textile furnishings that were created for display, or the pieces of jewellery and metalwork that were designed to contain such items, which appear in wills, inventories, codicils and chamber records. In these documents are mentioned tools and cosmetics in precious arks, jewellery, crockery, cloths and tablecloths, which sometimes seem to form a whole. Their shapes and forms, materials and purchase prices are mentioned, and occasionally even parts of their production process, or the professionals responsible for their design and production.

In the interpretation and contextualisation of this information, it is possible to describe some of the formal characteristics of amber jewellery, flasks, ewers, fruit and sweet confectionary. There is almost no record of preserved relics of table pieces and dressing tables, or anything other of that aesthetic or functional nature.

Their importance apart from elaborate aesthetic and economic value lies in their exclusive use. Many of the furnishings were essential objects of the outfit of a noble table, resulting in their being key elements in the protocol of noble ceremony and grandeur. Thus, the use of such items of luxury within a noble household became the distinction of a Lord or Lady.
\end{abstract}

Key words: Perfume bottles, comfit boxes, sensoriality, Castilian Court, $15^{\text {th }}$ Century.

\section{Introducción}

En este trabajo se han abordado -respetando la mentalidad de los contemporáneos que fabricaron y consumieron - tanto las obras de arte que se van a analizar como los productos que motivaron su creación. De esta forma se ha intentado profundizar en el ámbito del lujo cortesano, contemplando de manera interdisciplinar los elementos para el esplendor ambiental de la corte castellana de los tres primeros cuartos del s. $\mathrm{XV}$.

Los estudios previos consultados tratan de forma específica y en profundidad los objetos en sí: ajuar textil de mesa e instrumentos de orfebrería y joyería; los productos: cosmetología desde el punto de vista femenino, análisis de recetarios; e historia de las mentalidades desde un punto de vista sociológico: historia general del perfume, la alimentación, medicina y enfermedad en la Baja Edad Media... La aportación de este artículo es la puesta en relación, bien de objetos conservados o de los que se tiene noticia, con el uso y efecto sensorial para el que fueron creados, siendo el objetivo 
último ahondar en las obras artísticas dedicadas a la percepción exclusiva del gusto y el olfato.

Para su realización se han utilizado fuentes documentales y literarias contemporáneas, así como fuentes plásticas; y en los casos en que ha sido posible localizarlas, se han incluido obras conservadas. En primer lugar, se han consultado inventarios y libros de cámara correspondientes a diferentes miembros de la nobleza castellana, entre 1405 y 1486, conservados en el Archivo General de Simancas, la Sección Nobleza del Archivo Histórico Nacional, los archivos de las casas ducales de Alba, Medinaceli, Medina Sidonia y Alburquerque, así como el Archivo General de Andalucía y el Archivo Histórico Provincial de Burgos ${ }^{1}$.

El número total de la muestra asciende a cincuenta y un documentos (en torno a un $20 \%$ exceden el ámbito cronológico de este estudio); sin embargo, se han tenido en cuenta porque recogen noticias correspondientes a objetos en uso durante el periodo analizado. Las informaciones extraídas se refieren al nombre, procedencia, tipología, material, tamaño, grupos con que se asocia dentro de la cámara, y otros objetos con los que formaron conjunto. Dentro de las fuentes documentales, con el fin de reunir la mayor cantidad posible de información respecto al contenido de estos objetos, se han consultado cuatro manuscritos que albergan una gran variedad de recetas, de entre finales del s. XV y el s. XVI, y que parecen recoger una tradición anterior ${ }^{2}$.

A partir de estos datos, así como, de los materiales empleados para perfumes y confites, se ha podido elaborar un listado de materias primas, valor, sistema de producción, formato del producto manufacturado, contenedores y ámbito de uso. Entre las fuentes literarias se han manejado principalmente manuales de protocolo en la mesa, crónicas, y otras obras con noticias relacionadas, permitiendo contextualizar socialmente estos objetos, resolviendo por quién y de qué manera eran utilizados, y cuándo y para qué servían.

Respecto a las fuentes plásticas, se han utilizado aquellas con las que poder realizar una correspondencia, bien a partir de los objetos mismos, de las escenas o de los usos representados en ellas. Su atractivo reside en que dada la escasez de obras conservadas, ofrecen una imagen de las mismas que hemos considerado imprescindible para un estudio completo. No obstante, dado su uso exclusivo y personal, así como la exquisitez que se deduce de algunas de sus descripciones, parece difícil que las piezas, en especial vajilla y mantelerías, correspondan a representaciones completamente fidedignas de su diseño. A esto ha de sumarse que en la mayoría de los casos, no se

\footnotetext{
1 Durante la realización de este trabajo hemos tenido constancia de otras fuentes documentales que serían susceptibles de aportar información en el Archivo del Monasterio de Nuestra Señora de Guadalupe, en especial las correspondientes a la Cámara de María de Aragón, estudiadas por D. PELAZ FLORES, "Lujo, refinamiento y poder. La Cámara de Doña María de Aragón (1420-1445)", Actas del VI Simposio Internacional de jóvenes medievalistas, Lorca, 2012.

2 Madrid, Biblioteca Nacional de España (en adelante BNE): MSS/8565 Vergel de señores, s. XV; BNE: MSS/6058 Recetas y memorias, $\mathrm{s}$. XVI; BNE: MSS/1462 Livro de receptas de pivetes, pastilhas e lvvas perfumadas y conserbas, s. XVI. Madrid, Biblioteca de Palacio Real (en adelante BPR): II/1393(6) Receutas en nombre del doctor Segura, s. XVI. Igualmente hemos considerado datos correspondientes al manuscrito Mss. Parmense 834 (antes HH.V.163), 1475-1525, conservado en la Biblioteca Palatina de Parma, a partir del estudio monográfico de A. MARTÍNEZ CRESPO, Manual de mugeres en el qual se contienen muchas y diversas reçeutas muy buenas, Salamanca, 1995.
} 
trata de formas minuciosamente representadas, como las que se encuentran en otros territorios contemporáneamente. Esta información ha servido para establecer una tipología de objetos, atendiendo a sus materiales, a su uso, y cuando ha sido posible, a sus formas.

\section{La sensorialidad del lujo: olores y sabores}

La importancia de la imagen como herramienta para la configuración de poder entre la nobleza castellana en la corte Trastámara, ha sido ya ampliamente estudiada. Sin embargo, existirían otros elementos más allá de la sensorialidad visual, a la hora de generar el marco estamental de la aristocracia. Mientras que la apariencia creada a partir del traje o el vestido de la casa se dedicaría a la formación de una imagen de poder hacia el exterior, determinados aromas y sabores sirvieron para generar una fastuosidad accesible solo a los círculos más íntimos. Estos elementos aluden en primera instancia a efectos ambientales ${ }^{3}$ compuestos por aromas, que serían compartidos simultáneamente en actos ceremoniales, como a veces aparece reflejado en las crónicas $^{4}$, vinculados a la mesa, donde tendría lugar un segundo nivel de percepción exclusivo, en este caso individual, asociado a los sabores.

Más allá de estos tres niveles perceptivos, en los que los elementos sensoriales se hacen sucesivamente más propios, para la mentalidad de la época no parece existir una disociación entre los materiales dedicados a crear olores o sabores, ya que muchas veces se utilizan indistintamente para producir confites o perfumes. Su significación reside en el valor que se da a ambos como consolidadores, en términos espirituales, de la fortaleza del que los disfruta, llegando a contarse entre las medicinas más apreciadas para determinados males, tanto de índole emocional ${ }^{5}$ como físico $^{6}$.

3 Sobre la utilización del perfume para generar ambientes purificados mediante la quema de leñas aromáticas de enebro, ciprés, romero..., en cuyas brasas se esparcían perfumes, véase R. SANCHO DE SAN ROMÁN, Tres escritos sobre pestilencia del Renacimiento Español. Fernando Álvarez. Diego Álvarez Chanca. Licenciado Fores, Salamanca, 1979, pp. 92-94 y 113.

4 “[...] Despues que entraron dentro en la casa, fallaronla muy guarnida de paños Franceses, [...], é todas las cámaras é salas estaban dando de sí muy suaves olores". Á. LUNA, Crónica de D. Álvaro de Luna, condestable de los reynos de Castilla y León, Madrid, 1784, p. 193.

5 "Por calidat, que es la terçera via, manda traer buenos olores y suaues, asy como almizque, y anbra, y lignaloe, y galbano, y vnglan odorifera, y calamo aromatico, y cauos, y cortezas de mançanas y de çidras, y nuezes de çipres, porque son de buen olor. Estas cosas confortan los espiritus del que lo trae, y faze(n) fuerte su complixion, por benefiçio cordial contra el venenoso ayre, depurandolo y rretificando con su calentura y fragançia, y auferendo del rressultinuamente toda mixtion estraña. Para esto avn aprouecha las buenas aguas, asy commo muscada, y agua de azahar, y de rromero, y de melones, y de vinagre, y las buenas vnturas, commo el vnguento del alabastro, y el cibbo del azeyte del almastiga, y de zaubac, y tales cosas [...]". E. de VILLENA, Heurística a Villena y los tres tratados, Editorial Nacional, 1977, p. 44.

6 En BNE, MSS/8565, Libro Quarto, Capítulo XIII: De las pastillas que se azen para perfumes, fol. 211v: "[...] La otaba rreçeta tanvién es de mucha costa / como la sétima, pero es muy eçellente y non / solamente sirbe para perfumes, pero tóme/se por la boca para confortar maravillosamente / el coraçón, y el çelebro y el estómago e hígado / quando estén develitados [...]". Otras recetas ambivalentes que recoge el mismo manuscrito son: Maçapán para los tísicos, o Del azeite rosado que sirbe para olor y tanbién para medeçinas. 
La asociación entre el buen olor y la salubridad explica que los gestos de limpieza personal en la mesa se limitaran a las partes visibles ${ }^{7}$, y que el aseo se llevara a cabo en seco o mediante la aplicación de perfumes ${ }^{8}$.

A la percepción olfativa de la sahumadura de la estancia, se sumaría la de aromas y sabores que se superpondrían a esta base, compartida cuando se consumieran confites, frutas o en general los platos de una comida o cena. El encuentro con cada uno de estos estímulos se cuidaría de ser ofrecido de manera individual, de tal forma que pudiera disfrutarse en su integridad; esto se llevaría a cabo mediante el cuidadoso cambio del plato u objeto de vajilla correspondiente al término de cada servicio9.

Según las fuentes literarias, parece existir una diferenciación entre el uso social o íntimo de perfumes y confites. En el caso de los primeros, se vinculan al señor entre los muebles que revisten su casa en sentido material y metafórico; mientras que la utilización de ungüentos y afeites de consumo personal se ligan a la intimidad femenina ${ }^{10}$. Sin embargo, la documentación demuestra que materiales para perfumes aparecen, tanto en inventarios femeninos como masculinos, entre piezas de vidrio, plata, joyas y lienzos, con los que convivirían en la cámara. Cómo se producía la entrada en la cámara de estos bienes ha podido estudiarse en el Libro Maestro de la Casa de Alba ${ }^{11}$, que contiene la compra de materiales para confites y perfumes, y sus contenedores.

\section{Tipos de perfumes ${ }^{12}$ y confites}

La mayoría de los ingredientes enumerados en los documentos servían, indistintamente, para la elaboración de confites o perfumes, formando parte de entradas de gastos que incluían todo tipo de elementos suntuarios, normalmente lienzos, telas e

7 R. E. RÍOS LLORET y S. VILAPALNA SANCHÍS, “Joyas y sociedad”, Revista de Historia Moderna, 25 (1999), p. 9. Las crónicas contemporáneas ofrecen imágenes de este habitual gesto: “[...] despues todos los maestresalas uno en pos de otro venian á la dicha sala con el aguamanos, [...]", Memorial Histórico Español: colección de documentos, opúsculos y antugüedades que publica la Real Academia de la Historia. Crónica del Condestable Miguel Lucas de Iranzo, Año de 1464, vol. VIII, Real Academia de la Historia, 1855, p. 466.

8 G. VIGARELLO, "Del agua que se infiltra. La abertura de la piel. El aseo seco", Lo limpio y lo sucio, La higiene del cuerpo desde la Edad Media, Madrid, 1991, pp. 19-35.

9 "[...] E cada manjar que mudare le mude platel, porque en linpio sea puesto e se no buelvan los sabores en confusión de las viandas, o muestre mengua o poquedat de baxilla [...]", E. DE VILLENA, Arte Cisoria o tratado dell'arte de cortar del Culchillo, Barcelona, 1984, p. 80.

10 " [...] Tanto curaron los Antiguos de esta linpieza en el ofiçio del cortar que non solamente las dichas guardar cosas curaron, aun mas de ungüentos odoríferos las manos se ungían, asý como con el tiblo, e las ungüentarias de lodamo, e tales cosas de que non curé aquí de tractar porque esto en los omnes bien non paresçe, segúnd el uso deste tienpo, e mas conviene a las mugieres en sus afeytes. [...]", Ibid., p. 64.

11 Madrid, Archivo Ducal de la Casa de Alba (en adelante ADCA), Libro Maestro General de todas las rentas del estado de Alba. Agradecemos a Don José Manuel Calderón Ortega su ayuda en la consulta de este documento.

12 Las técnicas más comunes a la hora de elaborar perfumes eran la maceración y la destilación. Para saber más sobre estos procesos durante la Edad Media véase: I. LEVEQUE-AGRET, "Les parfums à la fin du Moyen Age: les différentes formes de fabrication et d'utilisation", Les Soins de Beauté, Centre d'Études Médiévales de Nice, 1987, pp. 135-144. 
hilos, aparentemente utilizados para la confección de manteles y hazalejas; que en muchas ocasiones parecen comprarse al mismo mercader o incluso joyero.

Las bases aromáticas más comunes empleadas en la elaboración de perfumes eran el benjuí y el estoraque -ambas de origen vegetal, y por ello más baratas-y el ámbar, la algalia y el almizcle -de procedencia animal- ${ }^{13}$.

Los formatos para el perfume eran: jabones -comunes, de Nápoles o valencianos-, pastillas, pebetes, adobos, polvillos, cuentas, almohadillas, aguas y aceites. Entre los perfumes ya manufacturados, encontramos: agua rosada, agua y aceite de azahar y romero, aceite de benjuí; además de bálsamos, lináloe, polvos de Alejandría y sahumaduras.

En cuanto a los confites, sus ingredientes son comunes a muchos de los que utilizamos actualmente. Se utilizan tres tipos de azúcar -candé, portugués y valenciano-, frutos secos, frutas, miel y numerosas especias como la canela o el anís. Se producen por confitura u horneado, y entre los preparados más habituales están la carne de membrillo, los confites de anís y valencianos, el diacitrón, los mazapanes, los piñonados, las suplicaciones y los canutillos. Los confites y el diacitrón se mencionan continuamente asociados; se venden por cajas, de las que no se especifica el peso, resultando las de diacitrón unas seis veces más caras que las de confites ${ }^{14}$.

\section{Mobiliario para el gusto y el olfato}

El mobiliario que alberga perfumes y confites comprende metales preciosos, vidrios y lienzos exquisitos. Todos ellos se recogían para su guarda, y cuando era necesario su transporte, en muebles de los que se cuidaba su capacidad para mantener aromas ${ }^{15}$, además de su consistencia y dignidad estética, dado que podían ser mostrados públicamente en especial si contenían útiles de mesa.

\section{Mobiliario textil}

El mobiliario textil contenido en los libros de cámara e inventarios que aparecen en testamentos, codicilos, cartas de dote y arras, y tasaciones, abarca: tobajas de servicio; manteles de mesa, de aparador y de ración; hazalejas o paños de aguamanos, de servir y de plato; pañezuelos de mesa o de sahumaduras; sobremanteles y fruteros

13 En el manuscrito BNE, MSS/8565, encontramos sistemáticamente la ordenación de las diferentes formas de hacer una misma receta según su coste, determinado por la presencia de estos ingredientes.

14 J.M. CALDERÓN ORTEGA, El ducado de Alba la evolución histórica, el gobierno y la hacienda de un estado señorial (siglos XIV-XVI), Madrid, 2005, p. 369.

15 “[...] póngase en el arca buenos olores, asý como lináloe e madero de savina, e de açiprés e rama de romero, en que asentó el arco de los colores que es dicho iris, porque toma dende buen olor e suave. E si el arca fuese destos maderos, açiprés e savina, seríe mejor. Los agudos olores para esto non cunple[n], ansí como alánbar, almisque, algalia, e tales que con su fortaleza cada día usados farían dapño a la cabeça. Basta los suaves que dixe para quitar la olor que'l cuero toma quando está ençerrado. E que los estrumentos sientan a ello e no al cuero. Mayormente los paños que ende están tomarán los tales olores e fará[n] en ellos mayor aderençia e serán plasibles de tratar e sanos". E. DE VILLENA, op. cit., 1984, p. 65. 
de lienzo. Su material principal es la fibra vegetal, a la que se suman el hilo de oro, de seda y aplicaciones. En muchos casos se especifica que se trata de lino, cáñamo, estopa o estopilla, un material más basto, que podría referirse tanto al lino como al cáñamo; solo en algunos casos se menciona la fibra concreta, "manteles de lino".

En cuanto a la decoración, puede diferenciarse entre la tejida, bordada, por deshilado y aplicada. Los tejidos que se utilizan, son lienzos de Flandes, Olanda, Remes, Bretaña, Cambray, París, Castilla o de la tierra. Además de otras denominaciones geográficas, que probablemente se refieran a particularidades que identificarían a los tejidos por su labor o ligamentos, como es el caso de los "alemaniscos", los "de soles" y los de "buitrago". Otros tipos de tejido empleados para pañezuelos y hazalejas son la impla y el alfame.

Manteles, pañezuelos y hazalejas se confeccionaban a veces de la misma pieza de tejido, en juegos cuyas proporciones varían de las fuentes literarias, que recogen el número de prendas a usar por comensal; a la indicada en los documentos, donde se relacionan las hazalejas que corresponden a cada mantel, normalmente por pares; así encontramos desde un par de manteles por otro de hazalejas ${ }^{16}$, hasta seis hazalejas por usuario ${ }^{17}$.

Un apartado propio merecen los fruteros de lienzo, al tratarse de una tipología diferenciada del resto de prendas de la mesa, por poder contener frutas para su exhibición y degustación. La forma de estos objetos no ha podido deducirse, pero sí conocemos sus materiales, el lienzo y el guadamecí, y que al menos en algunos casos tendrían cabos o extremos ${ }^{18}$. Podían ir bordados con seda, e hilo de oro; entre las combinaciones descritas, aparecen grana y oro, azul y oro, pardillo y oro, verde y morado, verde y pardillo y por último oro con carmesí. Uno de sus recursos decorativos más habituales, a parte del bordado, era el deshilado ${ }^{19}$, con el que se combinaba. Podían ir a juego con hazalejas, decorados ambos con las armas ${ }^{20}$ bordadas igualmente en oro y seda. Además de confeccionarse en tejido de fibra vegetal, los fruteros también podían ser de cuero; por ejemplo, dos fruteros de guadamecí, uno grande y otro pequeño, junto con dos almofardillas de lo mismo.

En la Cámara de Juan II aparece información sobre el proceso de confección de cinco fruteros ${ }^{21}$ en olanda delgada, para los que la "hoilandera" utilizó cinco varas y dos tercias ${ }^{22}$, aproximadamente un metro de tejido por prenda, suponiendo que todos fuesen del mismo tamaño. Dos de ellos se decoran con cintas de seda alrededor, uno pardillas y otro negras. Se precisa que son para cuando el Rey "hace sala", por lo tan-

16 Sevilla, Archivo General de Andalucía (en adelante AGA), PRIEGO, 1141/600-633. Inventario a la muerte de Pedro Núñez de Herrera y Guzmán, II Señor de Pedraza. Pedraza, Segovia, 1430, fol. 5r.

17 E. DE VILLENA, op. cit., 1984, p. 77.

18 Sanlúcar de Barrameda, Archivo Casa Ducal Medina Sidonia (en adelante ACDMS). MEDINA SIDONIA, Leg. 913. Inventario de bienes de la Infanta Beatriz de Castilla. Sevilla, 1409, fol. 20r.

19 M.A. GONZÁLEZ MENA, Colección pedagógico textil de la Universidad Complutense de Madrid. Estudio e Inventario, Madrid, 1994, p. 48.

20 Véase Fig. 3.

21 Archivo General de Simancas (en adelante AGS), CySR, Leg. 42, fol. 1 - j, 3. Recámara de don Juan II año de 1453. Cargo data y gastos de lienzos de la tierra, Flandes, Holanda, Sevilla, Bretaña, Malinas y Cambray, de los que se encarga Alfonso de Ylliescas, mozo de cámara de Juan II rey de Castilla. 1453, fol. 2v.

22 Aproximadamente 4,75 metros de tejido. 
to es probable que se trate de prendas que se usarían solo en estas ocasiones, aunque no puede descartarse que existiesen otros de uso cotidiano.

\section{Orfebrería y joyería}

Los contenedores metálicos (Fig. 1) de oro, y en su mayoría, de plata dorada, estaban en estrecha relación con las prendas para vestir la mesa, anteriormente descritas. Formaban un conjunto mientras se comía, y cuando posteriormente quedaban en manos del repostero de la plata, quien envolvía copas, jarras y confiteros en paños de lienzo perfumados, para su guarda en arcas o incluso en sus propios estuches ${ }^{23}$. Las tipologías derivadas del uso, aunque no existe una diferenciación precisa, pueden dividirse para el cometido de este trabajo por su contenido, entre confiteros y perfumadores. Dentro de estos dos grandes grupos, hay que tener en cuenta el estado de la materia que albergaban; por ejemplo, los perfumes podían ser de carácter líquido, sólido, humeante, u oleoso.

Los asociados a frutas y confites incluyen los confiteros propiamente, limoneros para el zumo de naranjas, limones o granadas-, brocas con las que servir los confites, brocas y pereros (Fig. 2) -para pelar la fruta, sin tener que utilizar los dedos- ${ }^{24}$. Los confiteros no son abundantes en la documentación, si se compara con otros objetos de la vajilla ${ }^{25}$. Constaban de una pila, a la que a veces se sumaba un pie y un tapador, y sus decoraciones incluían juegos de blanco y dorado, y esmaltes. Aproximadamente la mitad de los confiteros aparecen vinculados a un personaje concreto a partir de sus armas o divisa (Fig. 3).

Los confiteros son uno de los objetos que más fácilmente pueden identificarse en las fuentes plásticas, porque a veces se destapan mostrando su contenido. Su forma, puede asociarse a algunas obras de orfebrería religiosa conservadas en la actualidad, que, si no fueron confiteros originalmente, sí compartirían las mismas partes básicas de su estructura.

Los limoneros por su parte constaban de un mango y solían tener asociada una cuchara o limonera. Una de las descripciones encontradas habla de un recipiente con astil de bordes dorados, con una bellota al cabo, que formaría conjunto con cuatro cucharas grandes blancas, junto con unos vasillos con bellotas, también dorados, y dos brocas para conservas pequeñas, con los botones dorados ${ }^{26}$.

\footnotetext{
23 “'.... La guarda deve ser estos istrumentos puestos en sus vaynas e vaseras, cerradas con ñudo sabido, en que aya señal secreto, [...]”. E. de VILLENA, op. cit., 1984, p. 74.

24 "El segundo estrumento o manera de aquellos estrumentos que dixe es brocas, [...] sirve para tomar alguna vianda e ponerla delante syn tañer de las manos, e pan e fruta, cortados o enteros. E pueden con aquellas dos puntas comer vianda adobada syn untarse las manos, e con la otra punta moras o nuezes, confites, gengibre verde e otros letuarios e cosas con ella fazer, [...] El perero [...] sirve para mondar menbrillos e peras, mançanas e peros puestos en la cuchilla dél, porque non lleguen a ello con la mano, [...]”. E. de VILLENA, op. cit., 1984, pp. 71-72.

25 En el conjunto de documentos consultados solo aparece un total de catorce confiteros.

26 ADCA, Libro Maestro, 1477, p. 955.
} 


\begin{tabular}{|c|c|c|c|c|c|c|c|c|c|c|c|c|c|c|c|c|}
\hline & 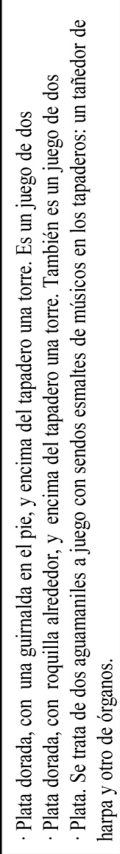 & 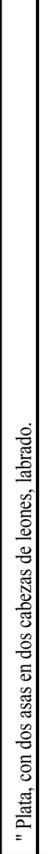 & 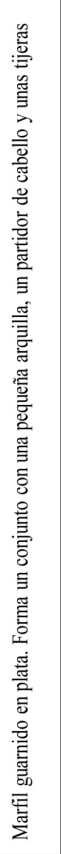 & 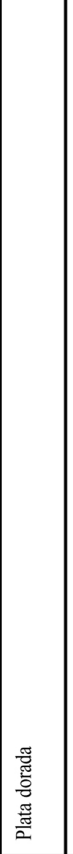 & 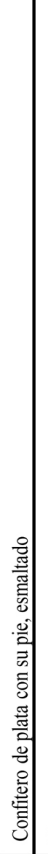 & 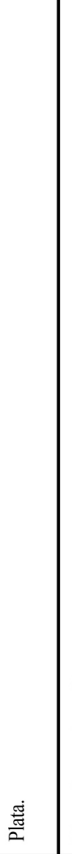 & 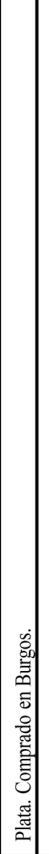 & 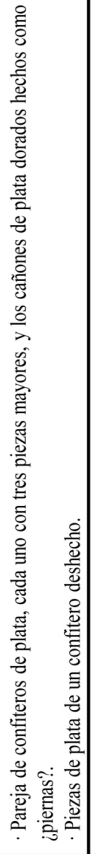 & 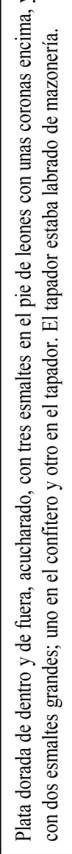 & 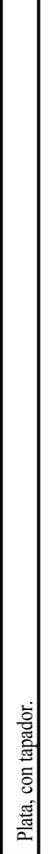 & 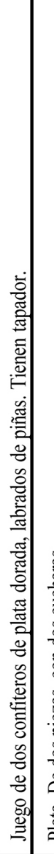 & 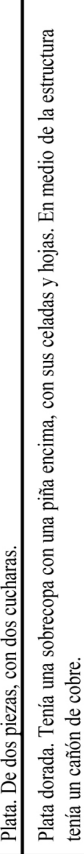 & 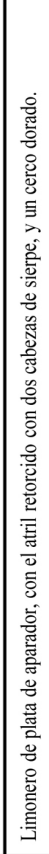 & 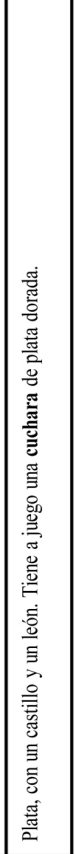 & 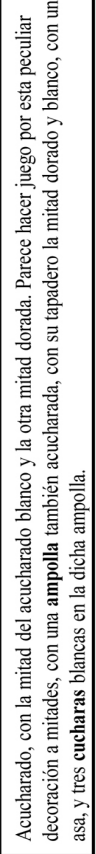 & 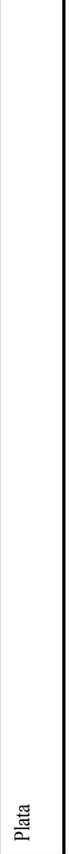 \\
\hline $\begin{array}{l}\text { ज्ञ } \\
\vdots \\
0 \\
0\end{array}$ & 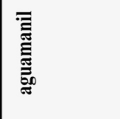 & 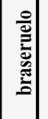 & 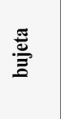 & 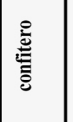 & & 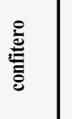 & 竎 & 窇 & 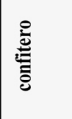 & 总 & & 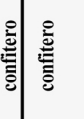 & 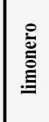 & 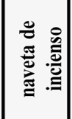 & 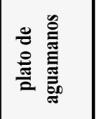 & 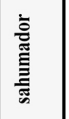 \\
\hline 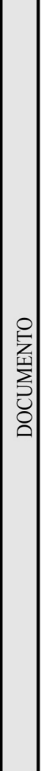 & 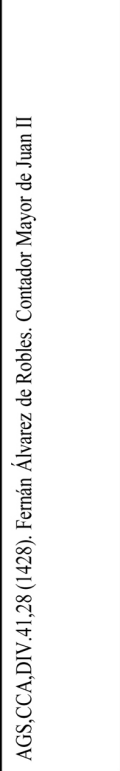 & 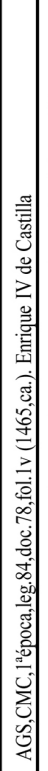 & 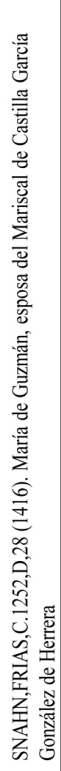 & 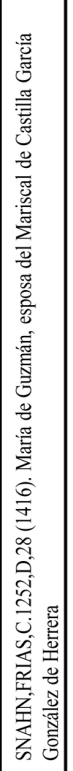 & 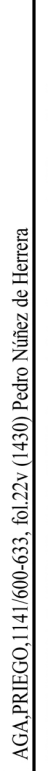 & 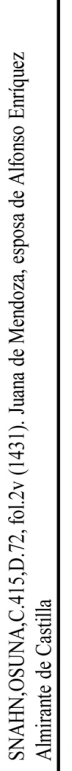 & 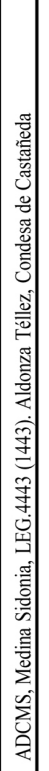 & 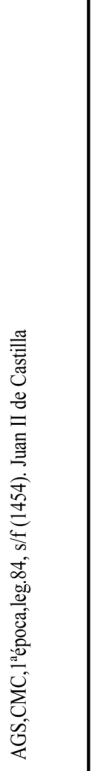 & 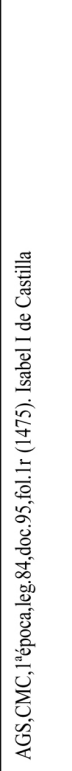 & 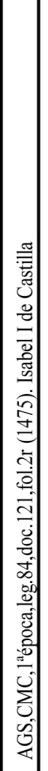 & 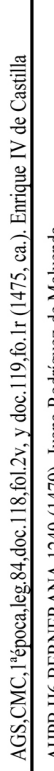 & 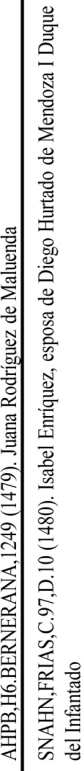 & 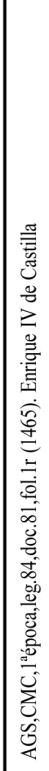 & 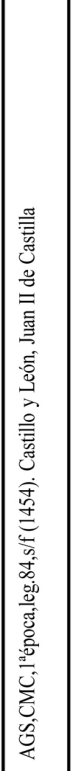 & 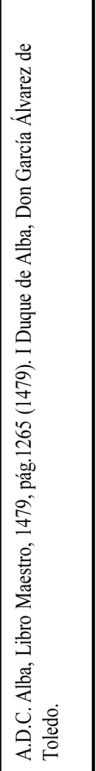 & 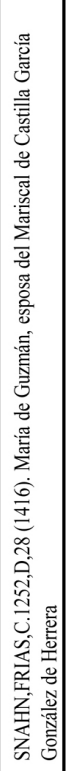 \\
\hline
\end{tabular}

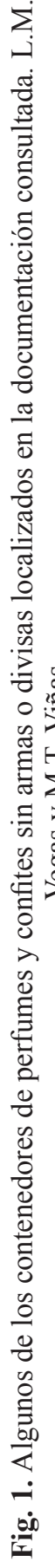


Dentro de la orfebrería, y entre los contenedores de perfumes, se encuentran: ampollas, pebeteros, sahumadores, perfumadores, incensarios, bujetas, candelericos ${ }^{27}$, braseros ${ }^{28}$ y aguamaniles. Estos últimos son los únicos que pueden conocerse con cierto detalle a través de los documentos y por conservar algunos ejemplos; eran de plata dorada con esmaltes, podían tener un cobertor, y solían acompañarse con una fuente, bacín o escudilla de aguamanos.

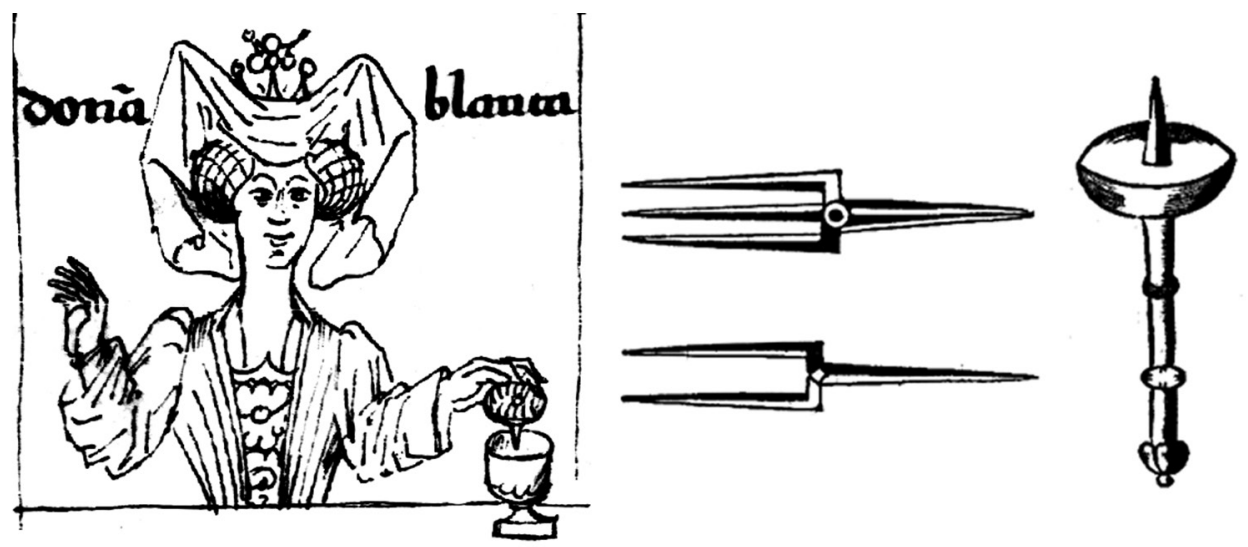

Fig. 2. Ilustraciones de brocas y pereros. E. VILLENA, Arte Cisoria o Tratado dell'arte del cortar del cuchillo, Madrid, Oficina de Antonio Marín, 1766, pp. 43 y 45; A. CARTAGENA, Genealogía de los Reyes de España, Biblioteca Palacio Real, MS II/3009, fol. 185v.

Parece ser que las fuentes eran una de las partes más ricas que formaban estos conjuntos; constaban de falda, suelo y ruedo. A veces se presentan en parejas y, al igual que los confiteros, podían asociarse a personalidades concretas. Junto con los confiteros, el grupo de los aguamanos es el más conocido, por las noticias literarias respecto a su uso ${ }^{29}$, así como por su relativamente fácil identificación cuando se representa en pinturas y miniaturas. De los incensarios, la documentación no aporta más datos de los ya conocidos a partir de las piezas conservadas: podían tener o no cadenas, y llevar un cobertor. Las bujetas se conservarían por su fragilidad dentro de cajas de madera, de las que se ha visto que pueden contener hasta seis. Estos pequeños objetos se llevarían en la mano, llenos de algalia, frutas u otros olores ${ }^{30}$, y podían formar conjunto con tijeras, separadores de cabello en una misma arquilla, todo en plata y marfil.

Las descripciones de joyas que incluyen ámbar no han podido diferenciarse como contenedoras de ámbar gris, o como realizadas en ámbar: es el caso de una manzana

27 Un perfumador y un candelero de plata para perfumes aparecen en Cuéllar, Archivo Casa Ducal de Alburquerque (en adelante ACDA), Ducado de Alburquerque, doc. 7, $\mathrm{n}^{\circ}$ 33, caja 7, $\mathrm{n}^{\circ}$ 24, fol. 1v y fol. 3v.

28 Un brasero pequeño de perfumes aparece en Toledo, Sección Nobleza, Archivo Histórico Nacional (en adelante SNAHN), FERIA, C.1D.4, fol. 5r.

29 "E despues que el Rey é la Reyna, é los otros caballeros, é dueñas é doncellas fueron á las mesas, traxeron el agua manos con grandes é nuevas cirimonias". Á. LUNA, op. cit., p. 193.

30 AGA, PRIEGO 1000/600-633, fol. 23r y fol. 25r.; SNAHN, FRIAS, C.1252, D, 28, fol. 14r y fol. 14v; SNAHN, OSUNA, C.214, D.125-126, fol. 1v; ACDA, Libro Maestro, 1476, p. 424. 


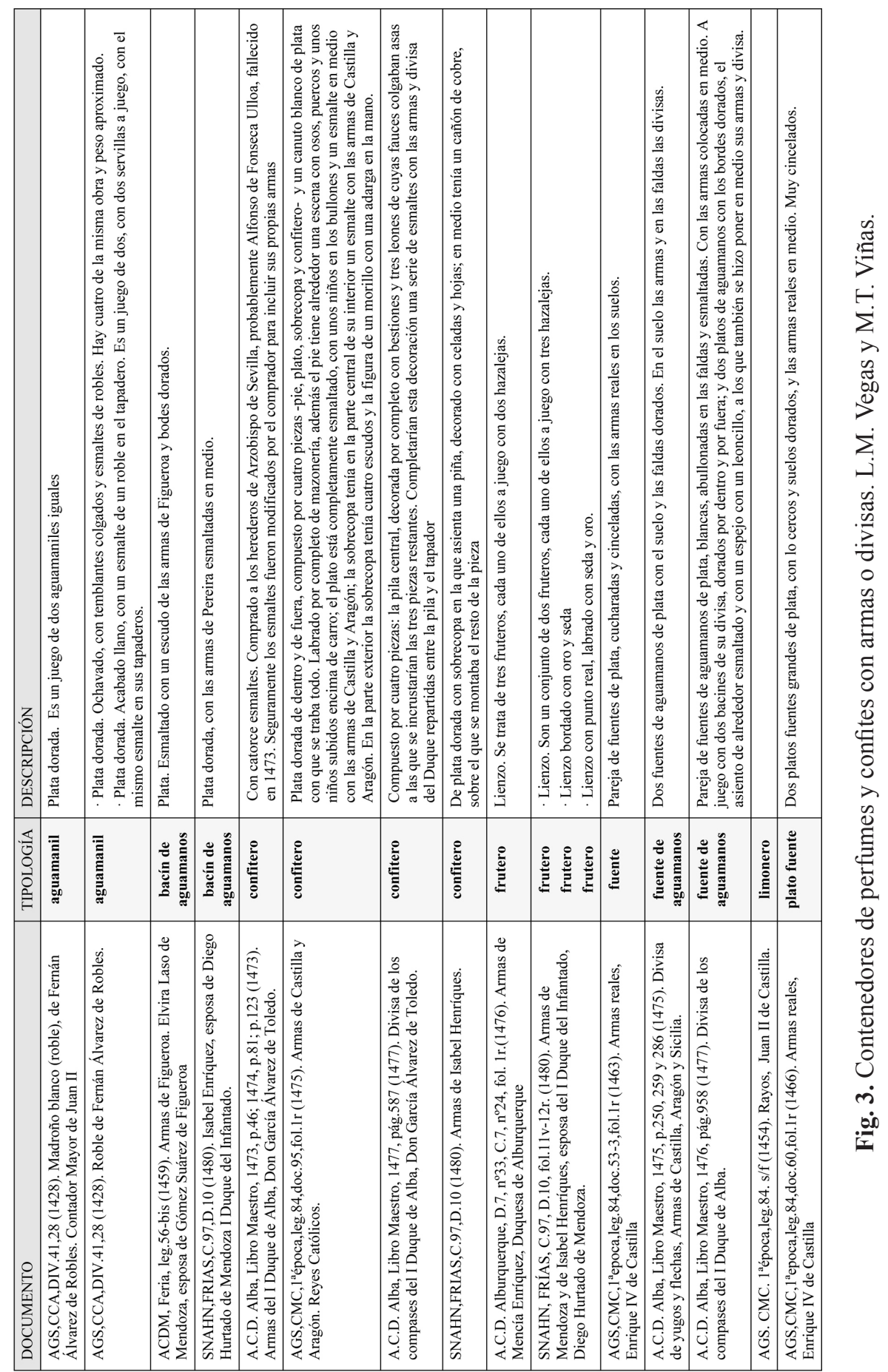


de "alámbar" engastada en una red de plata sobredorada con un cordel, al extremo del cual colgaría una manzanilla de granos de aljófar ${ }^{31}$; una pequeña venera de "alámbar" cadenilla de oro, y en el extremo una perla ${ }^{33}$.

Entre los contenedores realizados en otros materiales, encontramos redomillas, barrilejos, ampollas y canutillos de vidrio; sencillos papeles que envuelven almizcle y otros materiales; bujetillas de marfil guarnecido con plata, y otras de las que no se especifica su material, si bien en algunas se señala que son de color rojo. Otros contenedores son papos, cajas de palo o madera. Algunos formatos de perfumes generan su propio contendor: los rosarios ${ }^{34}$, formados por sartas de cuentas de olor, de lináloe y quizá también de ámbar, que podían aplicarse a joyas que llevar en la mano o prendidas, que desprenderían una mayor fragancia por contacto.

\section{Exclusividad y valor de continente y contenido}

El valor de perfumes y confites para la creación de un ambiente no solo agradable sino vigorizador para la salud y el ánimo propició su consumo más allá de las modas y elevado coste. A diferencia de lo que parece suceder con las formas estéticas de los contenedores, las recetas y los materiales se mantienen sin grandes variaciones desde finales del s. XV, hasta al menos bien entrado el s. XVI ${ }^{35}$.

Junto con las joyas, confiteros, aguamaniles... fueron utilizados como moneda de cambio recurrente por la nobleza castellana ${ }^{36}$. Por ejemplo, resulta especialmente interesante cómo uno de los prestamistas del Duque de Alba fue su proveedor de algalia, el mercader milanés Polo Ondegardo, al que da en prenda el confitero con su divisa ${ }^{37}$. La suma conseguida con esta y otras prendas, iba destinada al pago de paños para las celebraciones de la boda de la Duquesa de Alburquerque. Lo significativo de este gesto es que el Duque prescinda de su propio confitero, que junto con otras piezas de la vajilla, corresponderían a su aparador personal.

A parte del valor económico, el privilegio de uso y manipulación asociado a estas piezas, que tienen una impronta individual, redundaba en su exclusividad. Solo se confía a cargos oficiales otorgados en la cámara del señor o señora, con una función asignada concreta, ya fueran "reposteros de mesa", "reposteros de estrados", quie-

31 AGA, PRIEGO 1000/693-714, fol. 4v. En 1427 aparece entre los bienes de Isabel de Figueroa, y una joya de las mismas características está entre las posesiones de Elvira Laso de Mendoza en 1459: Toledo, Archivo Casa Ducal de Medinaceli (en adelante ACDM), Feria, leg. 56-bis, fol. 26v.

32 Ibid.

33 AGA, PRIEGO 11412/600-633, fol. 23v.

34 BNE, MSS/8565, Libro IV, De la pasta de Olor que se aze para traer en joyel o en poma, o para rrosarios y para en tiempo de pestilençia. fol. $215 \mathrm{r}$.

35 Véase nota 2.

36 Para el caso concreto de algunas de las piezas incluidas en este artículo, véase J.M. CALDERÓN ORTEGA, "Médicos, arrendadores y prestamistas judíos de la Casa de Alba durante el siglo XV", Proyección histórica de España en sus tres culturas, Castilla y León, América y el Mediterráneo, vol. I, Junta de Castilla y León, 1993, pp. 31-36.

37 Ver descripción del confitero en Fig. 3. 
nes se encargaban de ataviar los aparadores que contenían la vajilla; o "reposteros de plata", quienes guardaban y traían la plata a la sala. La fruta, y cabe pensar que también los fruteros de lienzo en que se llevaría a la mesa, estarían a cargo de los "mozos de despensa" 38 . El servir dentro de este protocolo constituía un privilegio ${ }^{39}$ practicado por los señores, según se refleja en las crónicas ${ }^{40}$, que también explican cómo en especial los perfumes, eran imprescindibles para el agasajo en las relaciones personales, además de mediante su manipulación en servicio del otro, como regalo diplomático ${ }^{41}$. Los guantes, adobados con diferentes aromas según su color ${ }^{42}$, debieron ser un regalo recurrente entre los miembros de la nobleza.

\section{Conclusiones}

Al tratar de llevar a cabo una asociación entre los datos de los documentos y sus representaciones en fuentes plásticas, no ha sido posible, pese a que los datos demuestran su existencia, identificar con claridad tanto los contenedores para perfumes y confites como estos mismos; por ejemplo, en el caso de los guantes no se puede afirmar que se trate de guantes adobados, porque obviamente es imposible justificar a través de su representación esta característica. La literatura menciona tigres odorífe$\operatorname{ros}^{43}$ y diversos materiales para perfumes ${ }^{44}$, que se han podido identificar con trufas o ámbar gris dentro de una caja de cristal ofrecida por uno de los Magos al Niño en

38 Sobre el protocolo en el servicio de la mesa, véase R. DOMÍNGUEZ CASAS, Arte y Etiqueta de los Reyes Católicos. Artistas, Residencias, Jardines y Bosques, Madrid, 1993, p. 223.

39 SNAHN, FRÍAS, C.2, D.1 Juan II concede a Juan Pacheco la merced de tener el cuchillo de la mesa del príncipe Enrique, con 30 maravedies diarios de ración. 1440, y SNAHN, OSUNA, C.36, D.1-22. Carta de merced del infante Enrique a Pedro Girón, Oficial del Cuchillo de su mesa, concediéndole los oficios de alcalde, alguacil y escribano público del concejo de Medina del Campo. Valladolid, 1444.

40 " [...] dó el señor Condestable le sirvió de maestresala y trinchante, y la señora Condesa su muger le dio el aguamanos y la copa, y asimismo la señora Juana, su hermana y otras donzellas servian la mesa de otras cosas, con tan jentil ayre y buena contenencia que era una maravilla [...]." Memorial Histórico Español: colección de documentos, opúsculos y antugüedades que publica la Real Academia de la Historia. Crónica del Condestable Miguel Lucas de Iranzo, año de 1464, vol. VIII, Real Academia de la Historia, 1855, p. 222.

41 "Y estando ansí el rey en Jaén, el rey de Fez le embió vn rico presente de almexías y almayzares y arreos de la gineta, e menjuy y estoraque y algalia y muchos otros olores para la reyna". D. DE VALERA, Memorial de Diversas Hazañas, Madrid, 1855, p. 45.

42 Esta debió de ser una práctica habitual, teniendo en cuenta que se han encontrado recetas en los cuatro manuscritos consultado: BNE, MSS/6058, fol. 129r a 130v, ofrece recetas para guantes amarillos, negros y blancos, entre otras. BNE, MSS/8565, fol. 200r a 206v, contiene recetas de adobo y perfume para las vueltas de los guantes. BNE, MS/1462, fol. 7r a 9v, con recetas para dar olor a lúas. BPR, MS.II/1393, fol. 78v a 79r, con una receta para buen olor y color, y fol. $82 \mathrm{r}$ con otra receta de menor coste.

43 "Y aun esta virtuosa ocasión, Rey muy poderoso, trahe a la vuestra real casa cada día las gentes estrangeras con diversos presentes y dones. [...] Vienen los de Garamanta y los pobres araxes, concordes en color con los etíopes por ser vezinos de la adusta y muy caliente zona, a vos ofreçer los tigres odoríferos". J. DE MENA, Sumas de la Yliada de Omero, Madrid, 1996, pp. 100-101.

44 "É Lope Alonso vino con él, con el qual el Rey de Túnez enbió al Rey presente de ropa delgada de lino é de seda, é de almisque é de algália é alámbar, é de otras muchas maneras de perfumes, é viniéron por tierra de África sesenta jornadas [...].” F. PÉREZ DE GUZMÁN, Crónica del Señor don Juan, segundo de este nombre en Castilla y en León, Imprenta de Benito Monfort, 1779, p. 254. 
la Adoración de Fernando Gallego del retablo de Arcenillas (Zamora), de en torno a 1490.

El estudio futuro de las recetas contenidas en los tratados contemporáneos podría aportar nuevos datos para el conocimiento de estos objetos, mediante la interpretación de los diferentes formatos y gestos de consumo que requerían. Dada la ausencia de objetos y sus representaciones en la corona de Castilla, otro recurso para profundizar en las tipologías sería la comparación de las referencias documentales con los conservados en cortes paralelas (Fig. 4$)^{45}$.

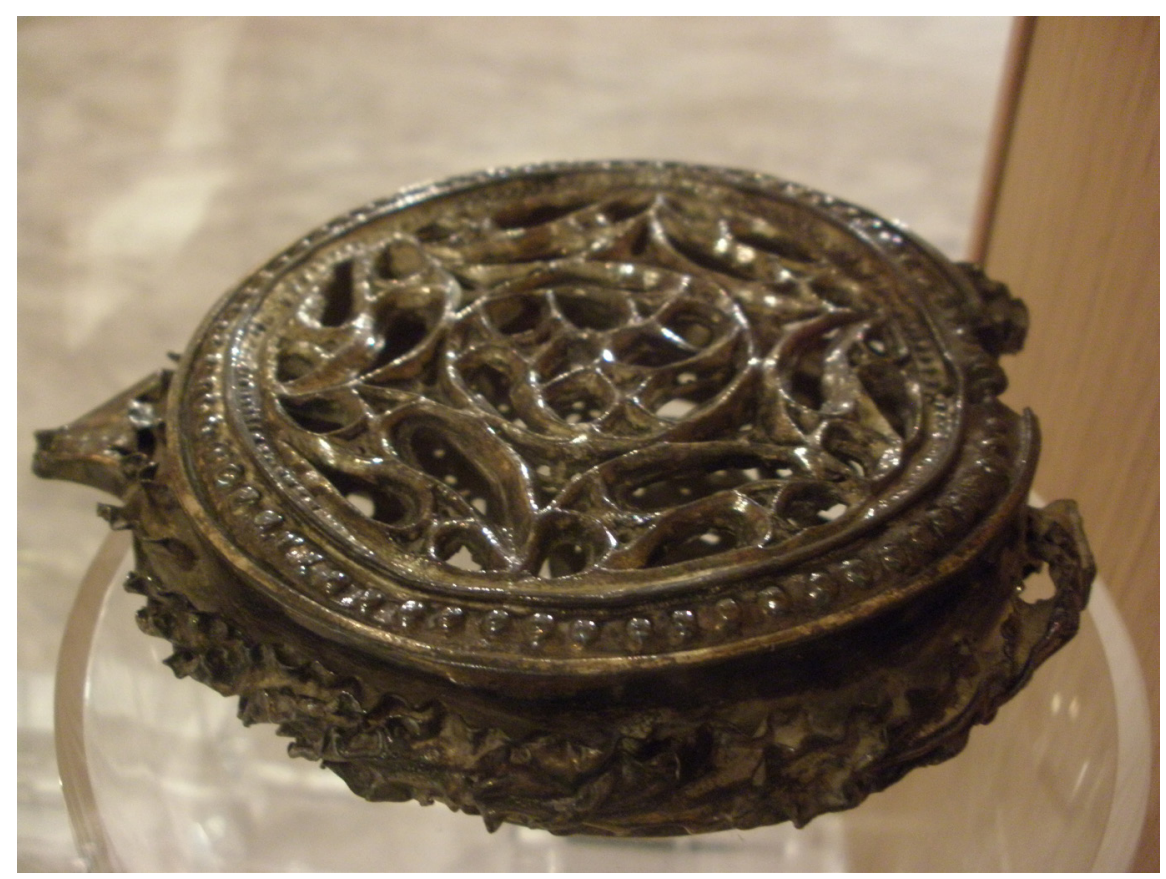

Fig. 4. Pebetero, s. XV. Hierro fundido. Valencia, Museo de Bellas Artes de Valencia, 425.

Han podido recogerse un total de once tipologías principales, entre objetos de metal, textil y cuero. De ellas tres - confitero, limonero y frutero- servían para el consumo de confites y frutas, y las ocho restantes -sahumadores, bujetas, aguamaniles o aguamanos, navetas de incienso, braseros para perfumes, platos fuentes y bacines de aguamanos- contenían perfumes o aguas perfumadas.

Los papeles, papos, redomillas, cajas, cornezuelos, etc. que constituían los envases de compra de estos productos eran sustituidos para su consumo por objetos creados por encargo o bien confeccionados en la propia cámara. El trabajo de los profesionales encargados de su diseño -hilanderas, bordadores, guadamacileros, lenceros,

45 Un ejemplo es el pebetero conservado en el Museo de Bellas Artes de Valencia, $\mathrm{n}^{\circ}$ 425. Agradecemos a David Gimilio Sanz la información sobre este objeto, del que se desconoce la procedencia. 
joyeros, doradores y plateros-, a parte de los mercaderes que proveían perfumes y confites o sus ingredientes, servirá también en el futuro para obtener nuevos datos.

La importancia de estas piezas está ligada en muchas ocasiones tanto a la riqueza como cantidad de sus materiales, motivo por el que el peso específico o las medidas de cada una de sus partes, son registrados con especial interés en los documentos, más allá de los colores o motivos de sus labores y en su caso esmaltes. Sorprende el peso de algunos de los confiteros hallados, de más de diez kilos, lo que condicionaría su uso respecto a otros objetos de la misma tipología de menores dimensiones. De esta manera cabe pensar en confiteros estáticos, decorados con las armas o divisas del señor, y otros que permitirían realizar el gesto de ofrecer. Detalles como el dorado interior y exterior, o la colocación en el interior de la tapa de las armas, confirmarían esta diferenciación.

En general, los confiteros presentan la doble dificultad de que, aunque su estructura es muy similar a la de relicarios, píxides, y copones, han llegado hasta nosotros con un uso diferente, y aunque sería lógico pensar dada su coincidencia estructural en confiteros (sobre todo para aquellos que no contienen inscripciones o iconografía religiosa), su contenido no aparece por lo general lo bastante detallado como para relacionarse con diacitrón, buñuelos, canutillos o cualquier formato de perfume. Por ejemplo, en el frontal de altar de la Capilla funeraria de los Ayala en Quejana (Álava), de $1396^{46}$, la escena central muestra cómo un Mago ofrece en un recipiente al Niño, que hace el gesto de tomar de su interior, algo que bien pudiera ser un confite. De entre los hostiarios conservados, que al ponerse en paralelo con los objetos que portan habitualmente los Magos de esta y otras muchas obras, sirve de ejemplo el conservado en el Museo Nacional de Artes Decorativas (Fig. 5) ${ }^{47}$.

$\mathrm{Al}$ igual que algunos confiteros, se han encontrado múltiples parejas de aguamaniles a juego, así como de fuentes y platos fuentes, que pueden tener además otras piezas combinadas, como bacinas, cucharas y ampollas. Otro ejemplo de objetos a juego serían los fruteros, ya descritos, y las bujetas: bien en medias docenas agrupadas en una misma caja, o en un cofre con otros objetos de aseo en el mismo material.

A parte de las tipologías mencionadas, se ha encontrado una bacina ${ }^{48}$ de plata grande que perteneció a Enrique IV, labrada de cincel, con cuatro asas doradas, con los bordes decorados con las armas reales, que pesaba 253 marcos y siete onzas (alrededor de sesenta y ocho kilos). Tenía además de las asas, un pie con seis pilares torcidos y en parte dorados, de los que asomaban sendos leones. Es la única pieza de estas características de la que se tiene noticia, y considerando las cuentas del boticario

46 The Art Institute of Chicago, inv. 1928.817.

47 Ver Fig. 5. De esta pieza se sospecha su dependencia de modelos profanos. Véase J.M. CRUZ VALDOVINOS, Platería en la época de los Reyes Católicos, Madrid, 1992, pp. 197-198. Respecto a su uso, que originalmente pudiera no ser religioso, véase la ficha del catálogo del museo realizada por J. ALONSO BENITO, URL: http://ceres.mcu.es/pages/Main (consultado 27/9/2013). Una caja redonda de plata blanca con las armas de Enrique IV, "de fechura de ostarie”, aparece en AGS, CMC, 1 a época, leg. 84, D.78, fol. 1r.

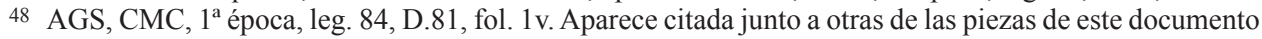
por M.A. LADERO QUESADA y M. CANTERA MONTENEGRO, "El tesoro de Enrique IV en el Alcázar de Segovia. 1465-1475", Historia, Instituciones, Documentos, 31 (2004), pp. 307-352. 
del Rey ${ }^{49}$, es muy probable que se utilizase con el mismo tipo de ingredientes que perfumes y confites, a lo que como ya se ha mencionado se atribuían propiedades curativas.

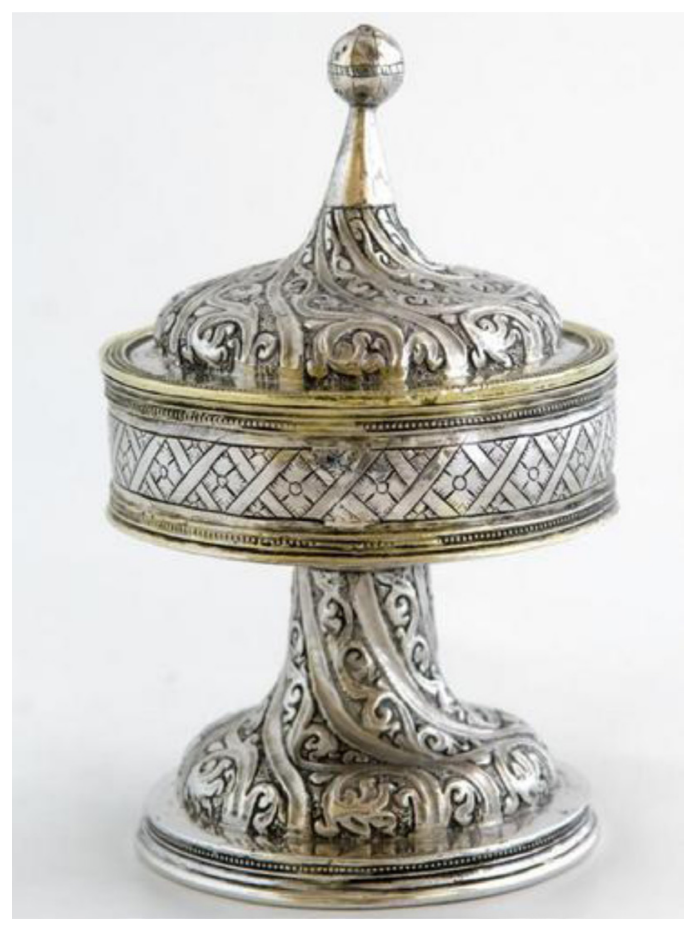

Fig. 5. Caja con pie, segunda mitad del s. XV. Plata sobredorada. Madrid, Museo Nacional de Artes Decorativas, CE00558. M. DEL AMO RODRÍGUEZ, Museo Nacional de Artes Decorativas, Catálogo de las Colecciones del Museo Nacional de Artes Decorativas. http:// ceres.mcu.es/pages/Main. Ministerio de Educación, Cultura y Deporte, España.

Aunque se ha procedido a la separación entre objetos con armas o divisas entre la decoración, y aquellos en los que no aparece mención expresa de estas, hay que considerar esta división como provisional, dado que muchos de los motivos representados, como es el caso de las piñas ${ }^{50}$ o los rayos, están siendo todavía objeto de estudio.

Un estudio estrictamente formal de las partes que componen perfumeros, fruteros y confiteros, además de las técnicas y labores para su decoración, permitirá en el futuro conformar una idea más precisa de cuál era su uso y valor estético, así como su papel en la configuración de los ambientes cortesanos, junto con aquellos bienes de consumo efímero con los que se emplearon para generar experiencias sensoriales complejas.

49 AGS, CySR, leg. 97.

50 Véase A. FERNÁNDEZ DE CÓRDOVA MIRALLES, "Las divisas del rey: escamas y ristres en la corte de Juan II de Castilla”, Reales Sitios, 191 (2012), pp. 22-37, y “El cordón y la piña. Signos regios e innovación emblemática en tiempo de Enrique III y Catalina de Lancaster (1390-1418)” (en preparación). 